\title{
DIFFERENCES IN DYNAMIC MODULUS OF ELASTICITY DETERMINED BY THREE VIBRATION METHODS AND THEIR RELATIONSHIP WITH STATIC MODULUS OF ELASTICITY
}

\author{
Shakti Chauhan ${ }^{1, \mathrm{~s}}$, Anil Sethy ${ }^{1}$
}

\begin{abstract}
Dynamic modulus of elasticity was determined in clearwood samples of eight tropical hardwood species using longitudinal vibrations, flexural vibration and ultrasonic transit-time methods. These samples were subsequently subjected to three point static bending test to determine static modulus of elasticity and modulus of rupture. Acoustic velocity and wood density were found to be independent parameters as the velocity was nearly the same in wood with distinctly different densities. Among the three dynamic measurements, modulus from the ultrasonic method was the highest followed by the longitudinal vibration and flexural vibration. Any of three vibration methods could be used to predict static modulus as they exhibited a near perfect correlation with static MoE. However, the dynamic modulus determined by different vibration methods were found to diverge with increasing static modulus. Wood density was the dominating factor influencing both modulus of elasticity and modulus of rupture.
\end{abstract}

Keywords: Acoustic, density, dynamic MoE, MoR, static MoE, ultrasonic.

\section{INTRODUCTION}

Non-destructive techniques based on vibration frequencies, stress wave and ultrasonic have become very popular in determining dynamic modulus of elasticity (DMoE) in wood and wood based structures. Several researchers have compared DMoE with Static MoE based on the studies carried out on clear wood samples, decayed wood, wood composites, sawn boards and logs and these methods have been reported to have moderate to strong association with static MoE (Wang et al. 2001, Yang et al. 2002, Lindsorm et al. 2004, Biechele et al. 2011). However different methods give different values of DMoE. Ultrasonic pulse transit time is reported to give the highest $\mathrm{DMoE}$ followed by stress wave transit time, longitudinal vibration frequency and flexural vibration frequency (Hains et al. 1996, Illic 2001, Hassan et al. 2013). The magnitude of difference in DMoEs determined by different methods is reported to be anywhere from $2 \%$ to $60 \%$ depending on the method used. Divos and Tanaka (2005) reported the effect of frequency of measurement on determination of modulus of elasticity and found higher MoE with increasing frequencies. Chauhan et al. (2005) reported $4 \%$ to $26 \%$ difference in acoustic velocity 
measured by resonance and transit time tool in laminated wood panels with different magnitude of in-homogeneity which in turn represent $8 \%$ to $52 \%$ difference in their DMoE. The difference was attributed to the mechanism of wave propagation in anisotropic wood medium. However, the difference between DMoEs determined by different methods for a wide range of wood density and static MoE is not yet completely understood. The discrepancies in DMoEs by different methods raise few concerns about the suitability of these methods for a range of species.

Application of non-destructive techniques on tropical timber species is still in infancy unlike in the temperate regions where the technologies have become commercially operational. Recently, Ponneth et al. (2014) reported strong relationship between wood mechanical properties measured by conventional method and DMoE by stress wave method in seven tropical hardwood species from India. The comparison of $\mathrm{DMoE}$ determined from different methods on range of species from low to high wood density and their relationship with static MoE and other mechanical properties is essential in order to develop the confidence in these non-destructive methods. In this study, DMoE was measured using three methods (ultrasonic, longitudinal vibration and flexural vibration) from clear wood samples of eight tropical timbers representing a range of wood densities. The strength of association of DMoEs with static MoE and other properties of wood was analyzed. The data was also analyzed for the difference in DMoEs determined from the three methods.

\section{MATERIALS AND METHODS}

Air-dried clear wood samples of eight species namely Bombax ceiba (Semul), Grevillea robusta (Silver oak), Mesopsis emmini (Mesopsis), Melia dubia (Malabar Neem), Acacia auriculiformis (Acacia), Eucalyptus hybrid (Eucalyptus), Hevea brasiliensis (Rubberwood), and Tectona grandis (Teak) were taken for the study. The dimension of the samples were $20 \mathrm{~mm}$ (Width) $\times 20 \mathrm{~mm}$ (Thickness) $\times 300 \mathrm{~mm}$ (Length) and the moisture content was around $12 \%$ at the time of measurement. Seven samples were taken for each species. The samples were weighed to an accuracy of $0,01 \mathrm{~g}$ and dimensions were measured to an accuracy of $0,01 \mathrm{~mm}$ using a digital caliper. Air dry density of the samples was determined from air dry weight and volume.

DMoE of the samples was determined from the resonance frequency of longitudinal and flexural vibrations and from the ultrasonic pulse transit time. In the resonance method, resonance frequencies of longitudinal and flexural vibrations were measured using an in-house developed acoustic tool. In the longitudinal vibration mode, the sample was supported over bubble wrap to create a near free-free boundary condition and gently tapped on the cross-cut face along the length using a small spherical headed hammer. A microphone was kept in the close vicinity at the other end of the sample (Figure 1 a). The microphone captured the time domain vibration signals. The inbuilt software transformed the time domain vibration signals to the frequency domain vibration spectra using the Fast Fourier Transformation (FFT) algorithm. The fundamental frequency of the longitudinal vibrations was recorded. The fundamental frequency $(f)$ of the longitudinal vibration gives the acoustic velocity in the material of length $l$ from the following relationship (Equation 1)

$$
V=2 f l
$$

$\mathrm{DMoE}$ from longitudinal vibration is derived from acoustic velocity from longitudinal vibration and wood density $(\rho)$ at the time of measurement using the following equation (Equation 2)

$$
D M o E_{\text {long }}=\rho V^{2}=4 \rho f^{2} l^{2}
$$

For flexural vibrations, the sample was supported at $0,22 \times$ length position over fishing thread 
attached to a custom built small jig. The tangential plane of the sample was kept facing upward direction. The microphone was placed close to the upper surface at one end (Figure 1b). The sample was gently tapped at the centre to induce flexural vibrations and the resonance frequency was recorded. The DMoE from flexural vibrations was calculated from the following equation (Equation 3):

$$
D M o E_{f l e x}=\frac{0,946 \rho f^{2} l^{4}}{h^{2}}
$$

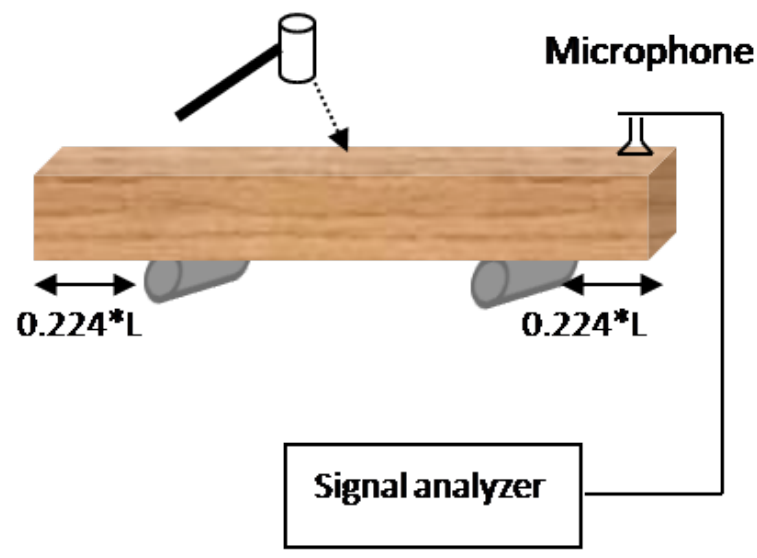

a)

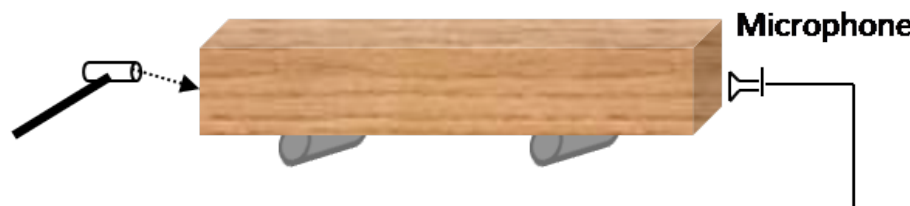

b)

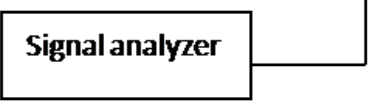

Figure 1. Set up for recording resonance frequency a) longitudinal vibrations b) flexural vibrations.

In ultrasonic method, transit time of an ultrasonic pulse of $50 \mathrm{KHz}$ frequency was measured along the length of the samples with an accuracy of 1 microsecond using a commercial ultrasonic timer tool. The tool was initially calibrated with a standard sample of polycarbonate. The standard transit time in $180 \mathrm{~mm}$ long polycarbonate cylinder was $65 \mathrm{~ms}$. Thereafter, ultrasonic pulse transit time was recorded over $300 \mathrm{~mm}$ long samples. The transducers (one inch diameter) were firmly coupled at both the ends with the help of petroleum jelly. The ultrasonic pulse velocity $\left(V_{u s}\right)$ was determined by dividing sample length by the recorded transit time and dynamic MoE was calculated using the following equation (4):

$$
D M o E_{u s}=\rho V_{u s}^{2}
$$

Subsequently, the samples were subjected to three point bending test using Shimadzu Universal Testing Machine as per Bureau of Indian Standards (IS-1708). The span length was $280 \mathrm{~mm}$ and the rate of loading was $1 \mathrm{~mm} / \mathrm{min}$. From the test, static MoE and modulus of rupture (MoR) were determined using the equations 5 and 6 respectively. 
where

$$
\begin{aligned}
M o E_{\text {stat }} & =\frac{P L^{3}}{4 D b h^{3}} \\
M o R & =\frac{3 P_{\max } L}{2 b h^{2}}
\end{aligned}
$$

P: Applied load at elastic limit $(\mathrm{N}), \mathrm{P}_{\max }$ : Maximum load $(\mathrm{N})$

L: Span length of test specimen (mm), b: Width of specimen ( $\mathrm{mm})$

$\mathrm{h}$ : Thickness of specimen (mm), D : Deflection at elastic limit (mm)

The data was statistically analyzed using MINITAB software. Tukey's pair-wise test was adopted to analyze the significant differences between species. Pearson's correlation analysis was used to examine the strength of linear association between different parameters and regression analysis was used to describe the relationship between variables.

\section{RESULTS AND DISCUSSION}

The species wise data on air dry density, acoustic velocity by longitudinal vibration, ultrasonic pulse transit time, $\mathrm{DMoE}_{\text {long }}, \mathrm{DMoE}_{\text {flex }}, \mathrm{DMoE}_{\mathrm{us}}$, Static $\mathrm{MoE}$ and MOR are shown in Table 1.

Table 1. Species wise mean values of various parameters. Value in parenthesis is standard deviation. Mean value for each parameter that do not share a superscript letter are significantly

\begin{tabular}{|c|c|c|c|c|c|c|c|c|}
\hline Species & $\begin{array}{c}\mathrm{AD} \\
\text { Density } \\
\left(\mathrm{kgm}^{-3}\right)\end{array}$ & $\begin{array}{c}\mathrm{Vel}_{\mathrm{res}} \\
\left(\mathrm{ms}^{-1}\right)\end{array}$ & $\begin{array}{l}\mathrm{Vel}_{\text {us }} \\
\left(\mathrm{ms}^{-1}\right)\end{array}$ & $\begin{array}{c}\mathrm{DMoE}_{\text {long }} \\
(\mathrm{GPa})\end{array}$ & $\begin{array}{c}\mathrm{DMoE}_{\text {flex }} \\
(\mathrm{GPa})\end{array}$ & $\begin{array}{c}\mathrm{DMoE}_{\text {us }} \\
(\mathrm{GPa})\end{array}$ & $\begin{array}{l}\text { Static } \\
\mathrm{MoE} \\
(\mathrm{GPa})\end{array}$ & $\begin{array}{l}\text { MOR } \\
(\mathrm{MPa})\end{array}$ \\
\hline $\begin{array}{l}\text { Mesopsis } \\
\text { emmini }\end{array}$ & $\begin{array}{c}357^{\mathrm{a}} \\
(24,06)\end{array}$ & $\begin{array}{l}5090^{\mathrm{a}} \\
(95,6)\end{array}$ & $\begin{array}{l}6366^{\mathrm{a}} \\
(148)\end{array}$ & $\begin{array}{l}9,25^{\mathrm{a}} \\
(0,87)\end{array}$ & $\begin{array}{l}8,41^{\text {a }} \\
(0,53)\end{array}$ & $\begin{array}{l}14,52^{\mathrm{a}} \\
(1,65)\end{array}$ & $\begin{array}{l}6,83^{\mathrm{a}} \\
(0,68)\end{array}$ & $\begin{array}{l}46,31^{\mathrm{a}} \\
(5,04)\end{array}$ \\
\hline Bombax ceiba & $\begin{array}{r}437^{b} \\
(40,80) \\
\end{array}$ & $\begin{array}{l}4571^{\mathrm{bc}} \\
(329)\end{array}$ & $\begin{array}{l}5823^{\mathrm{ab}} \\
(370) \\
\end{array}$ & $\begin{array}{l}9,16^{\mathrm{a}} \\
(1,45)\end{array}$ & $\begin{array}{l}8,35^{\mathrm{a}} \\
(1,09)\end{array}$ & $\begin{array}{l}14,85^{\mathrm{a}} \\
(2,08)\end{array}$ & $\begin{array}{l}7,04^{\mathrm{a}} \\
(0,97)\end{array}$ & $\begin{array}{l}59,55^{\text {ad }} \\
(9,44)\end{array}$ \\
\hline Melia dubia & $\begin{array}{l}577^{\mathrm{c}} \\
(66,9)\end{array}$ & $\begin{array}{l}4872^{\mathrm{ab}} \\
(183,8)\end{array}$ & $\begin{array}{l}6392^{\mathrm{a}} \\
(223) \\
\end{array}$ & $\begin{array}{l}13,64^{b} \\
(1,02)\end{array}$ & $\begin{array}{l}12,42^{b} \\
(1,74)\end{array}$ & $\begin{array}{l}23,60^{\mathrm{b}} \\
(3,00)\end{array}$ & $\begin{array}{l}10,13^{\mathrm{b}} \\
(0,89)\end{array}$ & $\begin{array}{l}89,44^{\text {bce }} \\
(10,88)\end{array}$ \\
\hline $\begin{array}{l}\text { Grevillea } \\
\text { robusta }\end{array}$ & $\begin{array}{c}614^{\mathrm{c}} \\
(28,50) \\
\end{array}$ & $\begin{array}{l}4156^{\mathrm{cd}} \\
(366)\end{array}$ & $\begin{array}{l}5414^{\mathrm{bc}} \\
(574) \\
\end{array}$ & $\begin{array}{l}10,61^{\mathrm{a}} \\
(1,42)\end{array}$ & $\begin{array}{l}9,50^{\mathrm{a}} \\
(1,20)\end{array}$ & $\begin{array}{l}18,04^{\mathrm{a}} \\
(3,00)\end{array}$ & $\begin{array}{l}7,80^{\mathrm{a}} \\
(1,00)\end{array}$ & $\begin{array}{c}76,28^{\text {bcd }} \\
(6,01)\end{array}$ \\
\hline $\begin{array}{l}\text { Hevea } \\
\text { brasiliensis }\end{array}$ & $\begin{array}{l}621^{\mathrm{c}} \\
(24,15) \\
\end{array}$ & $\begin{array}{l}3879^{\mathrm{d}} \\
(134)\end{array}$ & $\begin{array}{l}4880^{\circ} \\
(191) \\
\end{array}$ & $\begin{array}{l}9,36^{\mathrm{a}} \\
(0,90)\end{array}$ & $\begin{array}{l}8,79^{\mathrm{a}} \\
(0,91)\end{array}$ & $\begin{array}{l}14,81^{\mathrm{a}} \\
(1,50) \\
\end{array}$ & $\begin{array}{l}6,74^{\mathrm{a}} \\
(0,65)\end{array}$ & $\begin{array}{l}68,48^{\text {acd }} \\
(10,97) \\
\end{array}$ \\
\hline $\begin{array}{l}\text { Tectona } \\
\text { grandis }\end{array}$ & $\begin{array}{c}632^{\mathrm{c}} \\
(44,10) \\
\end{array}$ & $\begin{array}{l}4817^{\mathrm{ab}} \\
(253)\end{array}$ & $\begin{array}{l}6398^{\mathrm{a}} \\
(430) \\
\end{array}$ & $\begin{array}{l}14,70^{\text {bc }} \\
(1,95)\end{array}$ & $\begin{array}{l}13,60^{\mathrm{bc}} \\
(1,69) \\
\end{array}$ & $\begin{array}{l}25,99^{\text {bc }} \\
(4,43) \\
\end{array}$ & $\begin{array}{l}10,42^{\mathrm{bc}} \\
(1,28)\end{array}$ & $\begin{array}{l}98,86^{\mathrm{e}} \\
(14,22) \\
\end{array}$ \\
\hline $\begin{array}{l}\text { Acacia } \\
\text { auriculiformis }\end{array}$ & $\begin{array}{c}722^{\mathrm{d}} \\
(56,40)\end{array}$ & $\begin{array}{l}4816^{\mathrm{ab}} \\
(66,7)\end{array}$ & $\begin{array}{r}6361^{\mathrm{a}} \\
(75)\end{array}$ & $\begin{array}{l}16,77^{\mathrm{c}} \\
(1,66)\end{array}$ & $\begin{array}{l}15,53^{c} \\
(1,63)\end{array}$ & $\begin{array}{l}29,25^{\mathrm{c}} \\
(2,87)\end{array}$ & $\begin{array}{l}11,46^{\mathrm{bc}} \\
(1,27)\end{array}$ & $\begin{array}{l}96,05^{\text {be }} \\
(19,16)\end{array}$ \\
\hline $\begin{array}{l}\text { Eucalyptus } \\
\text { hybrid }\end{array}$ & $\begin{array}{c}726^{\mathrm{d}} \\
(27,34)\end{array}$ & $\begin{array}{l}4892^{\mathrm{ab}} \\
(302)\end{array}$ & $\begin{array}{l}6262^{\mathrm{a}} \\
(440)\end{array}$ & $\begin{array}{l}17,31^{\mathrm{c}} \\
(2,16)\end{array}$ & $\begin{array}{l}15,77^{\mathrm{c}} \\
(1,90)\end{array}$ & $\begin{array}{l}28,38^{\text {bc }} \\
(3,93)\end{array}$ & $\begin{array}{l}12,36^{\mathrm{c}} \\
(1,51)\end{array}$ & $\begin{array}{l}104,15^{\mathrm{e}} \\
(13,10)\end{array}$ \\
\hline
\end{tabular}
different $(n=7)$.

AD Density - Air Dry Density of wood; Vel - Acoustic velocity by resonance frequency of longitudinal vibration; Vel Acoustic velocity by ultrasonic; $\mathrm{DMoE}_{\text {long }}$-Dynamic MoE from longitudinal vibration; $\mathrm{DMoE}_{\text {fex }}$ - Dynamic MoE from flexural vibration frequency; $\mathrm{DMoE}_{\text {us }}$ - Dynamic MoE by ultrasonic pulse velocity; MoR - Modulus of Rupture. 
It is evident that these species represented a broad range of wood densities ( 357 to $726 \mathrm{~kg} / \mathrm{m}^{3}$ ). Among these species, density of Tectona grandis, Hevea brasiliensis, Grevillea robusta and Melia dubia were not statistically different. Mesopsis emmini exhibited the lowest density while Eucalyptus hybrid was the densest wood species. Interestingly, acoustic velocity, as measured from the resonance frequency of longitudinal vibrations, was the highest $(5091 \mathrm{~m} / \mathrm{s}$ ) in the lightest species (Mesopsis emmini). Acoustic velocity as measured by ultrasonic timer tool was statistically similar in six species despite large differences in their wood densities. Hevea brasiliensis wood with moderate wood density of $621 \mathrm{~kg} / \mathrm{m}^{3}$ exhibited the lowest acoustic velocities by both the methods. Despite the high acoustic velocity, dynamic and static $\mathrm{MoE}$ and $\mathrm{MoR}$ were the lowest for Mesopsis emmini and highest for Eucalyptus hybrid suggesting the greater influence of wood density in determining these properties.

Table 2. Pearson's correlation between various parameters.

\begin{tabular}{|l|l|l|l|l|l|l|l|}
\hline Parameter & $\begin{array}{c}\text { Density } \\
\left(\mathrm{kg} / \mathrm{m}^{3}\right)\end{array}$ & $\begin{array}{c}\text { Acoustic } \\
\text { velocity }(\mathrm{m} / \mathrm{s})\end{array}$ & $\begin{array}{c}\text { Ultrasonic } \\
\text { velocity }\end{array}$ & $\mathrm{DMoE}_{\text {Long }}$ & Static MoE & $\mathrm{DMoE}_{\text {flex }}$ & $\mathrm{DMoE}_{\text {us }}$ \\
\hline $\begin{array}{l}\text { Acoustic } \\
\text { velocity }\end{array}$ & $-0,21$ & & & & & & \\
\hline $\begin{array}{l}\text { Ultrasonic } \\
\text { velocity }\end{array}$ & $-0,04$ & $0,96^{* * *}$ & & & & & \\
\hline DMoE $_{\text {Long }}$ & $0,73^{* * *}$ & $0,50^{* * *}$ & $0,63^{* * *}$ & & & & \\
\hline Static MoE & $0,67^{* * *}$ & $0,59^{* * *}$ & $0,68^{* * *}$ & $0,99^{* * *}$ & & & \\
\hline DMoE $_{\text {flex }}$ & $0,74^{* * *}$ & $0,47^{* * *}$ & $0,61^{* * *}$ & $0,99^{* * *}$ & $0,98^{* * *}$ & & \\
\hline $\mathrm{DMoE}_{\text {us }}$ & $0,73^{* * *}$ & $0,51^{* * *}$ & $0,65^{* * *}$ & $0,99^{* * *}$ & $0,97^{* * *}$ & $0,98^{* * *}$ & \\
\hline MoR & $0,80^{* * *}$ & $0,31^{* *}$ & $0,44^{* *}$ & $0,89^{* * *}$ & $0,89^{* * *}$ & $0,88^{* * *}$ & $0,89^{* * *}$ \\
\hline
\end{tabular}

$\mathrm{DMoE}_{\text {long }}$-Dynamic $\mathrm{MoE}$ from resonance frequency of longitudinal vibration; $\mathrm{DMoE}_{\text {flex }}-$ Dynamic $\mathrm{MoE}$ from flexural vibration frequency; $\mathrm{DMoE}_{\mathrm{us}}$ - Dynamic MoE by ultrasonic pulse velocity; MoR - Modulus of Rupture.

The Pearson's correlation between various parameters for pooled data is shown in Table 2. There was no significant correlation between acoustic velocity (both by resonance and ultrasonic) and air dry density of wood. The scatter plot (Figure 2) demonstrate absence of any relationship between wood density and acoustic velocity in the studied material. This implies that density and acoustic velocity are two independent wood quality parameters. 


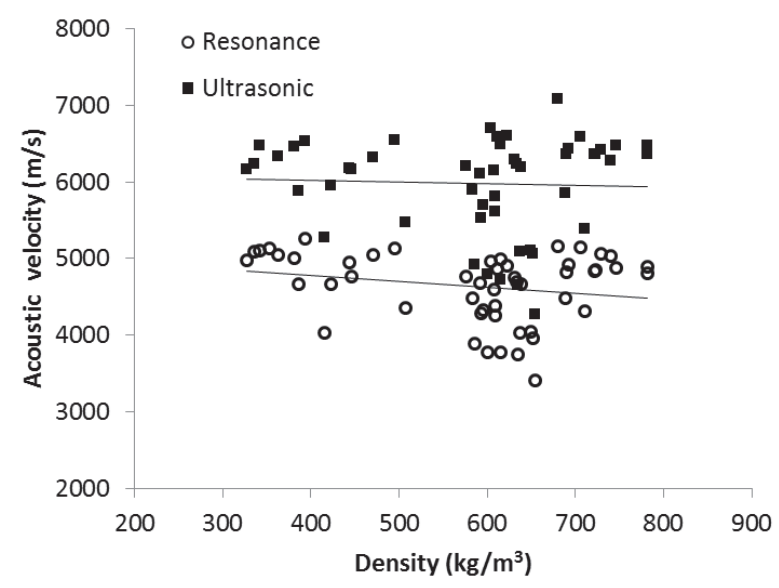

Figure 2. Relationship between acoustic velocity with wood density.

The results are in congruence with many other studies carried out on softwood and hardwood species. Hassan et al. (2013) reported the absence of significant association of wood density with acoustic velocity determined by ultrasonic and longitudinal vibration methods in Scots pine. Oliveira and Sales (2006) observed an increasing trend in ultrasonic velocity with density within a species in four Brazilian tropical timbers but the relationship was not significant when analyzed between species. Acoustic velocity is reported to have close association with microfibril angle (MFA) in cell walls (Chauhan and Walker, 2006) whereas wood density reflects the quantity of cell-wall material. The comparable acoustic velocity in low density and high density wood species suggests that there may not be significant differences in microfibril angle in these hardwood species. Hardwoods are generally known to have relatively small variation in MFA within and between species as compared to softwoods (Donaldson 2008). Zhang et al. (2011) reported a very similar MFA in low density Simarouba amara and high density Symphonia globulifera. They also reported that the specific dynamic modulus is highly correlated with the microfibril angle in wood.

Wood density was found to have a strong positive association with both modulus of elasticity (dynamic and static) and MOR. Interestingly, the correlation coefficient of DMoE with wood density was much higher than with acoustic velocity. This also indicates that in hardwoods, density is the dominant factor influencing both $\mathrm{MoE}$ and MoR. The correlation of MoR with acoustic velocity was not statistically significant. Similar observations have been observed even in case of mature wood of Douglas fir (Lachenbruch et al. 2010). They attributed the strong influence of wood density on MoE and MoR to the mature quality of wood in the studied samples. In juvenile wood of softwood species, acoustic velocity was found be a better predictor of MoE than wood density (Chauhan and Walker 2006, Lindström et al. 2004). In this study, the wood samples were extracted from mature timber. 


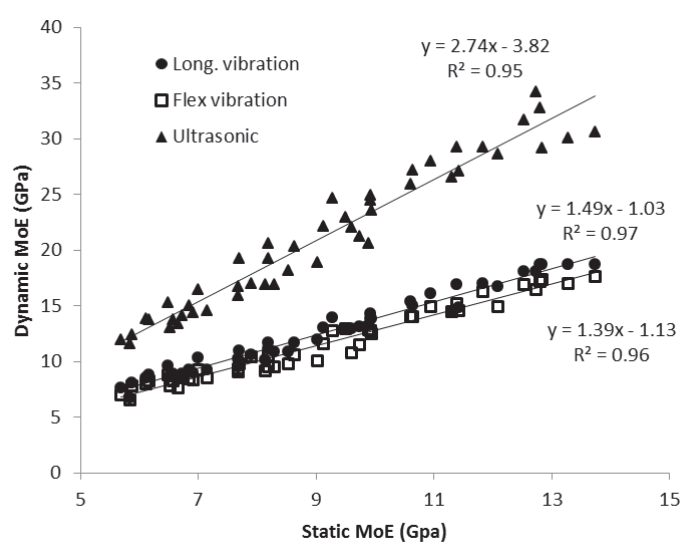

Figure 3. Relationship between dynamic MoE determined by different methods with static MoE.

DMoEs by three vibration methods exhibited very strong positive correlation with static MoE ( $\mathrm{r}$ $>0,96$ ). The relationship between static and DMOEs is given in Figure 3 and the regression equations represents the model equations describing the association. These model equations can suitably be used to predict the static MoE from dynamic MoE depending on the method adopted.

As expected the DMoE by ultrasonic is the highest followed by the longitudinal vibration and flexural vibration. DMoE by ultrasonic method was about $125 \%$ higher than static MoE. Such a large difference has not been reported earlier. Barr et al. (2015) reported 37-48,5\% difference in DMoE as measured from ultrasonic pulse velocity using Fakopp ultrasound timer ( $45 \mathrm{KHz}$ sensor) and static $\mathrm{MoE}$ in five hardwood species. One of the possible reasoning for the different DMoEs by vibration methods is the differences in the frequencies (Divos and Tanaka, 2005). In this case, the frequency of ultrasonic probe was $50 \mathrm{kHz}$, whereas longitudinal vibration frequencies ranged from 5,7 to $8,8 \mathrm{kHz}$ and flexural vibration frequencies ranged from 0,78 to $1,11 \mathrm{kHz}$. In many cases, the accuracy in measuring transit time also cause discrepancies in single pass timer tools, particularly over short distances, due to pulse propagation time within the transducers. In this study, the ultrasonic timer was calibrated before every set of measurement with a standard calibration sample provided with the instrument thereby avoiding any probability of error in data due to time correction factors. A significantly higher ultrasonic pulse velocity or $\mathrm{DMoE}_{\mathrm{us}}$ in these samples may be attributed to the mechanism of pulse propagation in the anisotropic and attenuating wood medium. Molyneux and Schmitt (2000) suggested that a small amplitude signal associated with dilatational energy moves at a much higher speed along with the fastest available path in highly attenuating media that can have a discrete onset of signal arrival. The picking - up of these signals depends on their amplitude, attenuation of the signal, stiffness of the fastest available path in anisotropic media, measuring system's onset threshold and signal amplification. The arrival of dilatational energy may easily be detected by the systems in short and dry wood samples as the signal attenuation is relatively low in dry wood. In this case, the presence of latewood band (which is denser and stiffer as compared to earlywood) provides the fastest path for ultrasonic pulse and therefore the measured ultrasonic velocity or dynamic MoE may be influenced by the properties of latewood. However this needs further investigations.

The study also revealed that the difference in DMoEs measured by any of these three methods was not constant over the entire static MoE range. The slope of the equations relating $\mathrm{DMoE}$ to static $\mathrm{MoE}$ was different in all three cases and was highest for ultrasonic method $(2,74)$ followed by longitudinal vibration $(1,49)$ and flexural vibration method $(1,39)$. It was observed that the DMoEs were diverging with the increasing static MoE. The difference in $\mathrm{DMoE}$ by ultrasonic method and flexural vibration method with respect to static MoE is shown in Figure 4. 


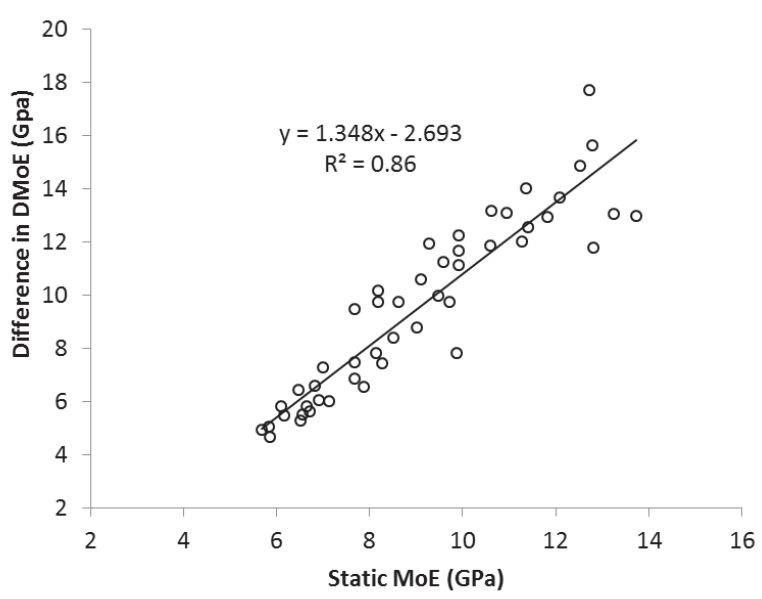

Figure 4. Trend in difference in DMoE by ultrasonic method and flexural vibration method with respect to static MoE. The difference continue to increase with the increase in static MoE.

The difference ranged from 4,66 to 17,70 GPa over the entire range of static MoE. The magnitude of divergence of $\mathrm{DMoE}_{\text {long }}$ with $\mathrm{DMoE}_{\text {flex }}$ was little and therefore the two regression lines appeared parallel. The increasing difference in DMoEs with static MoE may also be attributed to the wave propagation mechanism, as discussed earlier. It is well known that speed of stress wave pulse depends on the Young's modulus and density of the material. Chauhan et al. (2005) have shown that acoustic velocity by longitudinal vibration is the function of the volume weighted average stiffness of the entire sample under the test. Therefore, DMoE from resonance frequencies (longitudinal or flexural vibrations) remain unbiased from the localized variations within the sample and are more close to the static MoE. However, in ultrasonic pulse method the high frequency waves travels at a relatively faster speed in stiffer and denser material thus resulting in diverging differences in DMoEs with the increasing static MoE.

\section{CONCLUSIONS}

The study demonstrates that in hardwood species, dynamic modulus is strongly influenced by the wood density rather than acoustic velocity or resonance frequency. Acoustic velocity and wood density were found to be independent parameters. Dynamic MoEs exhibited nearly perfect linear relationship with static $\mathrm{MoE}$ and therefore any of the vibration methods can effectively be used for predicting static MoE provided suitable regression models are developed over a wide range of static MoE values. This study reveals an interesting observation about the divergence in DMoEs determined by different methods with increasing static MoE. Modulus of rupture also exhibited a strong relationship with MoE and wood density. 


\section{ACKNOWLEDGEMENTS}

Authors express sincere gratitude to the Director, Institute of Wood Science and Technology, Bangalore for his support in carrying out this study. The authors are also thankful to Mr. Krishna and Mr. Jean Simon for their assistance during the course of this study.

\section{REFERENCES}

Biechele, T.; Chui, Y.H.; Gong, M. 2011. Comparison of NDE techniques for assessing mechanical properties of unjointed and finger-jointed lumber. Holzforschung 65(3): 397-401.

Barr J.; Tippner J.J.; Rademacher P. 2015. Prediction of mechanical properties - Modulus of Rupture and Modulus of Elasticity - of five tropical species by nondestructive methods. Maderas-Cienc Tecnol 17(2): 239-252.

Chauhan, S.S.; Entwistle, K.; Walker, J.C.F. 2005. Differences in acoustic velocity by resonance and transit-time methods in an anisotropic laminated wood medium. Holzforschung 59: 428-434.

Chauhan, S.S.; Walker J.C.F. 2006. Variation in acoustic velocity and density with age and their interrelationships in radiate pine. Forest Ecology and Management 229(1-3): 389-394.

Divos, F.; Tanaka, T. 2005. Relation between static and dynamic modulus of elasticity of wood. Acta Silvatica \& Lignaria Hungarica 1: 105-110.

Donaldson, L. 2008. Microfibril angle: Measurement, variation and relationships - A review. IAWA Journal 29(4):345-386.

Haines, D.W.; Leban, J.M.; Herbe, C. 1996. Determination of Young's modulus for spruce, fir and isotropic materials by the resonance flexure method with comparisons to static flexure and other dynamic methods. Wood Science and Technology 30: 253-263.

Hassan, K.T.; Horacek, P.; Tippner, J. 2013. Evaluation of strength and stiffness of scots pine wood using resonance frequency and ultrasonic techniques. Bioresources 8(2): 1634-1645.

Ilic, J. 2001. Relationships among the dynamic and static elastic properties of air-dry Eucalyptus delegatensis R. Baker. Holz als Roh- und Werkstoff 59: 169-175.

Lachenbruch, B.; Johnason; G.R., Downes G.M.; Evans R. 2010. Relationships of density, microfibril angle and sound velocity with stiffness and strength in mature wood of Douglas-fir. Canadian Journal of Forestry Research 40: 55-64.

Lindström, H.; Harris, P.; Sorensson, C.T.; Evans, R. 2004. Stiffness and wood variation of 3-year old Pinus radiata clones. Wood Science and Technology 38: 579-597.

Molyneux, J.B.; Schmitt, D.R. 2000. Compressional-wave velocities in attenuating media: a laboratory physical model study. Geophysics 65:1162-1167. 
Oliveira, F.; Sales, A. 2006. Relationship between density and ultrasonic velocity in Brazilian tropical woods. Bioresource Technology 97: 2443-2446.

Ponneth, D.; Anoop, E.V.; Jayasree, C.E.; Aadarsh, M.; Chauhan, S.S. 2014. Destructive and non-destructive evaluation of seven hardwoods and analysis of data correlation. Holzforschung 68(8): 951-956.

Wang, X.; Ross, R.J.; McClellan, M.; Barbour, R.J.; Erickson, J.R.; Forsman, J.W.; Mcginnis, G.D. 2001. Nondestructive evaluation of standing trees with stress wave method. Wood Fiber Science 33(4):522-533.

Yang, J.L.; Ilic, J.; Wardlaw, T. 2002. Relationships between static and dynamic modulus of elasticity for a mixture of clear and decayed eucalypt wood. Australian Forestry 66 (3): 193-196.

Zhang, T.; Bai, S.L.; Bardet, S.; Alméras, T.; Thibaut, B.; Beauchêne, J. 2011. Radial variations of vibrational properties of three tropical woods. Journal of Wood Science 57: 377-386. 